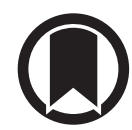

CrossMark

\title{
Lung function in the children of immigrant and UK-born south-Asian mothers
}

\section{To the Editor:}

There are ethnic differences in lung function, with white subjects having larger height-normalised forced vital capacity (FVC) and forced expiratory volume in $1 \mathrm{~s}$ (FEV 1 ) than black people or Asians [1, 2]. It has been argued that these differences might be explained by environmental and social factors associated with poverty $[3,4]$. Alternatively, the differences in lung volume might be explained by inherent factors, such as genetically determined differences in body frame, with a relatively smaller thoracic cage and, consequently, smaller lungs in some Asian ethnic groups $[4,5]$. If the differences were explained mainly or entirely by environmental exposures, lung function in populations migrating from a south-Asian to a western European country should increase in successive generations as standards of living gradually approach those of the host region.

We recently reported that FVC and FEV1 were 11\% and 9\% lower in UK-born south-Asian children compared with their white peers, but that these differences were not explained by cultural and socioeconomic indicators, perinatal data, environmental exposures, or personal or family history of wheeze [6]. However, such analyses always include the possibility of residual confounding by lifestyle factors or early-life environmental exposures that were not measured in the study and, hence, could not be accounted for in the analysis. If unmeasured environmental and lifestyle factors explain ethnic differences in lung function [7], we would expect the lung function of the offspring of mothers born and raised in the host country to be more similar to that of the native population than that of children born to immigrant mothers. We tested this hypothesis by comparing spirometry in two groups of UK-born south-Asian children: those with immigrant mothers and those with UK-born mothers.

We studied a community-based, random sample of children born 1993-1997 in Leicestershire, UK [8]. Perinatal data and information on maternal age, ethnicity, country of birth, religion and language came from maternity records, and were validated with questionnaires. Parents answered repeated standardised questionnaires and a nested sample of 4100 children (1126 south-Asian children) was invited for spirometry in 2006-2010. Local research ethics committee approval and written consent were obtained. A large proportion of the Leicestershire population originates from south Asia (mainly Gujarat and Punjab) [9]. Our analysis grouped south-Asian children into 1) those whose mothers had migrated to the UK and 2) those whose mothers were UK-born.

Children performed spirometry (Pneumotrac; Vitalograph, Ennis, Ireland) before and after $400 \mu \mathrm{g}$ salbutamol. We recorded FVC, FEV1, peak expiratory flow (PEF) and forced expiratory flow at 50\% vital capacity (FEF50\%). The main outcome was post-bronchodilator lung function, reflecting structural lung development rather than reversible airway obstruction. We compared lung function between groups using multiple linear regression (Stata 11.2; Stata Corporation, Austin, TX, USA). Baseline analysis was adjusted for anthropometric data (height, weight (both linear and quadratic terms), age, sex, birth weight and gestational age); the full model was also adjusted for cultural and ethnic indicators (maternal language, religion, age at delivery, paternal country of birth and language), socioeconomic status (SES) (Townsend deprivation score, parental education, crowding and single parenthood), environmental exposures (preand post-natal maternal smoking, breastfeeding, cooking, heating, siblings, daycare, and pets), and personal (wheeze frequency, shortness of breath and asthma treatments) and family history of wheeze [6]. We used multiple imputation to deal with missing values in predictors [6]. In two sensitivity analyses, we excluded cases with missing values and analysed pre-bronchodilator lung function respectively.

A nested sample of 299 (27\%) out of 1126 south-Asian children participated. After excluding 24 children of mixed ethnicity, the lung function of 275 children (mean age 11.7 \pm 1.1 years) was analysed. Characteristics of participating families have been described previously $[9,10]$. Among mothers of south-Asian children, 70 (25\%) were born in the UK and 205 (75\%) had migrated (123 from India, 79 from Africa and three from elsewhere). Overall, $47 \%$ were of Hindu religion. Among fathers of 
south-Asian children, 78\% had migrated (97 from India, 107 from Africa and two from elsewhere) and $52 \%$ spoke either Gujarati or Punjabi. Compared with children of immigrant mothers (table 1), south-Asian children of UK-born mothers more often spoke English at home ( $49 \%$ versus $22 \%, \mathrm{p}<0.001$ ), were of Sikh religion ( $31 \%$ versus $11 \%, \mathrm{p}<0.001$ ), and had higher SES (low Townsend deprivation score $20 \%$ versus $10 \%, \mathrm{p}=0.006$ ), fewer siblings (no siblings $31 \%$ versus $25 \%, \mathrm{p}=0.038$ ) and less wheeze $(14 \%$ versus $27 \%, \mathrm{p}=0.036)$, but more parental asthma ( $26 \%$ versus $15 \%, \mathrm{p}=0.028)$. UK-born mothers were

TABLE 1 Characteristics of the study population by ethnic group ( $n=275$ )

South-Asian children

of immigrant mothers

South-Asian children

of UK-born mothers

p-value ${ }^{\#}$

\begin{tabular}{|c|c|c|c|}
\hline Children n & 205 & 70 & \\
\hline \multicolumn{4}{|l|}{ Demographic data } \\
\hline Males & $110(53.7)$ & $39(55.7)$ & $0.766^{++}$ \\
\hline \multicolumn{4}{|l|}{ Language } \\
\hline Punjabi & 23 (11.2) & $16(22.9)$ & \\
\hline English & $44(21.5)$ & $34(48.6)$ & \\
\hline Other & $39(19.0)$ & $5(7.1)$ & $<0.001^{++}$ \\
\hline Muslim & $59(28.8)$ & $16(22.9)$ & \\
\hline Sikh & $23(11.2)$ & $22(31.4)$ & \\
\hline Other & $3(1.5)$ & $0(0.0)$ & $<0.001^{++}$ \\
\hline \multicolumn{4}{|l|}{ Socioeconomic status } \\
\hline \multicolumn{4}{|l|}{ Townsend deprivation score tertile } \\
\hline Low & $20(9.8)$ & $14(20.0)$ & \\
\hline NQF 1-2 & $57(27.8)$ & $14(20.0)$ & \\
\hline NQF 3-5 & $52(25.4)$ & $32(45.7)$ & \\
\hline$N Q F \geqslant 6$ & $54(26.3)$ & 17 (24.3) & $0.042^{\S \S}$ \\
\hline Crowding $^{+}$ & $75(36.6)$ & $19(27.1)$ & $0.135^{++}$ \\
\hline Single parenthood & $12(5.9)$ & $4(5.7)$ & $0.615^{f f}$ \\
\hline \multicolumn{4}{|l|}{ Environmental exposures } \\
\hline Pre-natal maternal smoking" & $1(0.5)$ & $0(0.0)$ & $0.745^{f f}$ \\
\hline Post-natal maternal smoking" & $2(1.0)$ & $0(0.0)$ & $0.549^{f f}$ \\
\hline Breastfeeding" & $155(75.6)$ & 58 (82.9) & $0.258^{++}$ \\
\hline Cooking in house $\S^{\S}$ & $181(88.3)$ & $60(85.7)$ & $0.833^{++}$ \\
\hline Heating in house ${ }^{f}$ & $158(77.1)$ & $51(72.9)$ & $0.325^{++}$ \\
\hline \multicolumn{4}{|l|}{ Number of older siblings ${ }^{\pi}$} \\
\hline 0 & $51(24.9)$ & $22(31.4)$ & \\
\hline Doctor-diagnosed asthma & $63(30.7)$ & $15(21.4)$ & $0.245^{++}$ \\
\hline Parental history of asthma" & $30(14.6)$ & $18(25.7)$ & $0.028^{++}$ \\
\hline Parental history of hayfever ${ }^{ף}$ & $63(30.7)$ & $30(42.9)$ & $0.065^{++}$ \\
\hline
\end{tabular}

Data are presented as $\mathrm{n}(\%)$ unless otherwise stated. Percentages may not add up to $100 \%$ due to missing values. National Qualification Framework (NQF) 1-2 equates to GCSE (General Certificate of Secondary Education) examinations (usually taken at age 16 years), NQF 3 equates to A-level (Advanced Level General Certificate of Education) examinations (taken at age 18 years) and NQF 6 is equivalent to a university degree. ": comparing children of south-Asian immigrant mothers with children of south-Asian UK-born mothers. ": at time of recruitment. ${ }^{+}$: more than one person per room. ${ }^{\S}$ : gas only. ${ }^{f}$ : central only. ${ }^{\# \#}$ : in the 12 months prior to measurement; does not indicate that the child was symptomatic or receiving treatment at the time of measurement. "१ๆ: use of inhaled bronchodilators or corticosteroids. $\S^{\S}$ : test for trend. ${ }^{++}$: Chi-squared. ${ }^{f f}$ : Fisher's exact test. 
younger at the birth of the index child than immigrant mothers (mean \pm SD age $26.8 \pm 3.6$ versus 29.4 \pm 4.3 years, $\mathrm{p}<0.001$ ). Differences in environmental exposures measured in our study were small.

After adjusting for anthropometric data (baseline analysis), mean post-salbutamol FVC was not higher (as hypothesised) but similar or even marginally lower in south-Asian children of UK-born mothers compared with south-Asian children of immigrant mothers, with a relative difference (95\% CI) of $-3.4 \%$ (-6.7--0.2\%) ( $\mathrm{p}=0.039$; unadjusted results) (fig. 1). Post-salbutamol FEV1, FEV1/FVC, PEF and FEF50\% were similar in both groups with relative differences of $-2.0 \%(-5.5-1.6 \%), 1.6 \%(-0.2-3.5 \%),-1.8 \%$ $(-6.6-3.4 \%)$ and $0.6 \%(-6.0-7.8 \%)$, respectively (all $\mathrm{p}>0.1)$. Birth weight and age-adjusted height were similar in both groups (all $\mathrm{p}>0.2$ ). The full model adjusting for cultural and ethnic indicators, multiple environmental and socioeconomic variables, and personal and family history of wheeze, and the two sensitivity analyses yielded essentially similar results. Hence, when comparing the two generations of immigrants, there was no evidence for an increase in lung volumes or flows in south-Asian children of UK-born compared with those of immigrant mothers.

Taken together, this population-based study found no evidence of an increase in lung volumes from the first to the second generation of UK-born south-Asian immigrant children, despite improvements in SES. Assuming that environmental exposures of migrants, both measured and unmeasured, had become more similar to the indigenous population with succeeding generations, we had expected larger lung volumes in children with UK-born mothers compared with those with immigrant mothers. This was not the case and suggests that at least some of the differences in lung volumes might not be environmental, but inherent to the ethnic group, for instance, being explained by differences in body frame. However, our study was limited in sample size, in the number of generations studied (two), and in the range of socioeconomic and environmental differences between the generations. Differences in lung size caused by improved environmental conditions between successive generations might only be measureable if improvements are large. Although we found some differences in SES (table 1), the contrast between the two generations might not have been sufficient. Finally, lung growth in our subjects was not complete, leaving the possibility that differences might emerge as the children approach adulthood.

Studies examining differences in lung function in immigrant populations are rare. Larger lung volumes in young adult, US-born Indians compared with Indian-born subjects were attributed to early childhood environment [7] but with little information on the environmental factors that might vary between the groups. Our previous analysis found that differences of $9-11 \%$ in lung volumes between south-Asian and white children born and living in Leicester, UK, were unexplained by measured cultural, socioeconomic, perinatal or environmental factors [6]. However, we could not rule out residual confounding by unmeasured factors. Therefore, the question should be explored in future studies with large study populations, meticulous recording of SES, ethnicity, religion and region or origin of both parents [4], assessment of long-term outcomes including mortality [11], and, ideally, inclusion of several generations of immigrants. Such studies would also relieve the recognised need for more data on south-Asian populations [12].

In summary, our results do not support the hypothesis that ethnic differences in height-adjusted lung function are fully explained by nutritional, environmental or socioeconomic factors associated with living in a western society, and suggest that they are, at least partly, inherent to the ethnic groups. If this is true, genome-wide ancestry measurements [13] might improve prediction of lung function in ethnically mixed
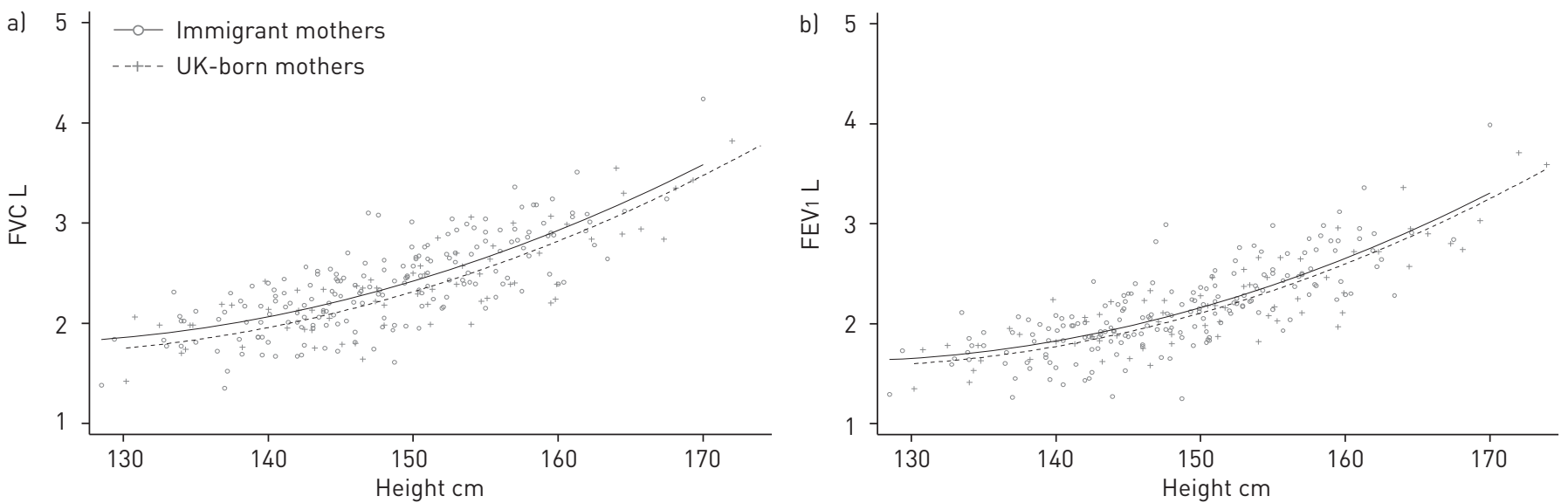

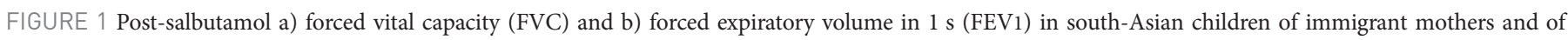
UK-born mothers (unadjusted results, $\mathrm{n}=275$ ). 
groups. Currently, published multiethnic values for spirometry [14] may not be appropriate for south-Asians, who may require ethnicity-specific reference equations even for populations that have been resident away from their region of origin for more than one generation.

\section{@ERSpublications \\ Lung function is similarly low in children of migrant and UK-born south-Asian mothers http://ow.ly/Fhs4e}

Claudia E. Kuehni ${ }^{1}$, Marie-Pierre F. Strippoli ${ }^{1,2}$, Ben D. Spycher ${ }^{1}$, Michael Silverman ${ }^{3}$ and Caroline S. Beardsmore ${ }^{1}$ Institute of Social and Preventive Medicine (ISPM), University of Bern, Bern, Switzerland. ${ }^{2}$ Dept of Psychiatry, Lausanne University Hospital, Prilly, Switzerland. ${ }^{3}$ Division of Child Health, Dept of Infection, Immunity and Inflammation, University of Leicester and Institute for Lung Health, Leicester, UK.

Correspondence: Claudia E. Kuehni, ISPM, University of Bern, Finkenhubelweg 11, CH-3012 Bern, Switzerland.

E-mail: kuehni@ispm.unibe.ch

Received: Aug 192014 | Accepted after revision: Nov 262014 | First published online: Jan 82015

Support statement: This study was supported by the Swiss National Science Foundation (grant 3200B0-122341) and Asthma UK (grant 07/048). B.D. Spycher was supported by a Swiss National Science Foundation fellowship (PZ00P3_147987). Funding information for this article has been deposited with FundRef.

Conflict of interest: Disclosures can be found alongside the online version of this article at erj.ersjournals.com

Acknowledgements: We thank the parents and children of Leicestershire and Rutland, UK, for participating, and Tony Davis (Specialist Community Child Health Services, Leicester City Primary Care Trust, Leicester, UK) for his assistance.

\section{References}

1 Donnelly PM, Yang TS, Peat JK, et al. What factors explain racial differences in lung volumes? Eur Respir J 1991; 4: 829-838.

2 Schwartz J, Katz SA, Fegley RW, et al. Sex and race differences in the development of lung function. Am Rev Respir Dis 1988; 138: 1415-1421.

3 Burney P, Hooper R. Ethnicity and ventilatory function: a response to Professor Quanjer. Int J Tuberc Lung Dis 2013; 17: 568.

4 Braun L, Wolfgang M, Dickersin K. Defining race/ethnicity and explaining difference in research studies on lung function. Eur Respir J 2013; 41: 1362-1370.

5 Quanjer PH. Lung function, race and ethnicity: a conundrum. Eur Respir J 2013; 41: 1249-1251.

6 Strippoli MP, Kuehni CE, Dogaru CM, et al. Etiology of ethnic differences in childhood spirometry. Pediatrics 2013; 131: e1842-e1849.

7 Fulambarker A, Copur AS, Cohen ME, et al. Comparison of pulmonary function in immigrant $v$ s US-born Asian Indians. Chest 2010; 137: 1398-1404.

8 Kuehni CE, Brooke AM, Strippoli MP, et al. Cohort profile: the Leicester respiratory cohorts. Int J Epidemiol 2007; 36: 977-985.

9 Kuehni CE, Strippoli MP, Low N, et al. Asthma in young south Asian women living in the United Kingdom: the importance of early life. Clin Exp Allergy 2007; 37: 47-53.

10 Kuehni CE, Strippoli MP, Low N, et al. Wheeze and asthma prevalence and related health-service use in white and south Asian pre-schoolchildren in the United Kingdom. Clin Exp Allergy 2007; 37: 1738-1746.

11 Burney P, Hooper R. Lung function, genetics and ethnicity. Eur Respir J 2014; 43: 340-342.

12 Quanjer PH, Brazzale DJ, Boros PW, et al. Implications of adopting the Global Lungs Initiative 2012 all-age reference equations for spirometry. Eur Respir J 2013; 42: 1046-1054.

13 Berube JC, Lamontagne $\mathrm{M}$, Couture $\mathrm{C}$, et al. Genome-wide genetic ancestry measurements to predict lung function in European populations. Eur Respir J 2013; 42: 1144-1147.

14 Quanjer PH, Stanojevic S, Cole TJ, et al. Multi-ethnic reference values for spirometry for the 3-95-yr age range: the global lung function 2012 equations. Eur Respir J 2012; 40: 1324-1343. 